\title{
Equipment Quality Importance Evaluation for Wind/Photovoltaic Energy Storage and Transmission Demonstration Project via Index System and Cluster Analysis
}

\author{
Long Jiang ${ }^{\mathrm{a}}$, Lei Du ${ }^{\mathrm{b}}$ \\ North China Electric Power Research Institute Co Ltd. Beijing 100045, China \\ akaveykikiy@163.com, bdulei426311@163.com
}

\begin{abstract}
Keywords: Wind/Photovoltaic Energy Storage and Transmission Demonstration Project, Index System, Cluster Analysis, Equipment Quality Importance.
\end{abstract}

\begin{abstract}
. 22 kinds of equipment for wind/photovoltaic energy storage and transmission demonstration project were selected to establish the equipment quality importance index system via their operation and quality supervision data. Then, the evaluation results were combined with the cluster analysis to further classify them from the view of equipment quality importance. The results show that: 22 kinds of equipment can be divided into 3 categories; for specific index in index layer, the equipment quality importance sequence was different with each other due to different function and performance of each equipment; for indexes in target layer and criterion layer, the equipment quality importance sequence was similar, representing the overall role of each equipment in wind/photovoltaic energy storage and transmission project.
\end{abstract}

\section{Introduction}

With the gradual depletion of fossil fuels in recent years, the restricting effect of energy resources on the economic growth of society became more and more intensive [1]. The development of efficient, clean and renewable energy has turned into an importance measure to reduce energy consumption and govern the air pollution. Under the background and structure of energy consumption, the exploitation and utilization of renewable energy sources get rapid development in China [2]. The wind/photovoltaic energy storage and transmission project was the first "Golden sun demonstration project", which was jointly launched by the Ministry of finance, the Ministry of science and technology, the National Energy Bureau and the National Power Grid Corp, possessing the largest wind power and photovoltaic power generation, energy storage and smart transmission capability in the world [3].

The rapid development of electric power industry carry out the challenge for the equipment quality: the "double reverse" occurs commonly at the international level; more and more intensive domestic price war; some suppliers gain profits via reducing the quality of products, resulting in increasing product faults in the operation process. In order to promote the products quality, reduce fault rate, ensure the safety of equipment operation, the management of the equipment quality for wind/photovoltaic energy storage and transmission project is the key. Because of abundant equipment type and amount, only with the aid of manual quality information record is not enough to carry on the management work for wind/photovoltaic energy storage and transmission demonstration project. Thus in this paper, 22 kinds of equipment used in the wind/photovoltaic energy storage and transmission project were selected to establish the equipment quality importance index system via their operation data and quality supervision data to achieve classification regulation.

\section{Index System Establishment}

22 essential equipment for wind/photovoltaic energy storage and transmission project were selected in this paper to evaluate equipment quality importance: wind generator, wind turbine tower, transformer, reactor, switchgear, circuit breaker, isolating switch, box type substation, wind turbine blades, photovoltaic inverter, cable, current transformer, voltage transformer, capacitor, switch 
cabinet, polycrystalline silicon PV modules, cables, fittings, insulators, cable branch box, lightning arrester, cable accessories. By using the analytic hierarchy process [4], the evaluation index system of quality problem for wind/photovoltaic energy storage and transmission equipment was established, which contains three layers: target layer (reflecting the overall importance of equipment quality problems)-criterion layer (equipment importance index, equipment quality problem index, equipment management index)-index layer (specific evaluation index of each equipment). The specific index system was shown in Table 1.

The range analysis method was employed to standardize each index value for eliminating the magnitude difference between different indexes [5] (the index values of wind generator were taken as standard values in this paper). When the bigger index value reflects more important equipment quality problem:

When the smaller index value was the better situation:

$$
y_{i j}=\left(x_{i j}-x_{j \min }\right) /\left(x_{j \max }-x_{j \min }\right)
$$

$$
y_{i j}=\left(x_{j \max }-x_{i j}\right) /\left(x_{\text {jmax }}-x_{\text {jmin }}\right)
$$

Then, the mean square difference method was used to calculate each index weight in different layers [6]:

$$
\begin{gathered}
E_{j}=\frac{1}{22} \sum_{i=1}^{22} y_{i j} \\
\sigma_{j}=\sqrt{\frac{1}{22} \sum_{i=1}^{22}\left(y_{i j}-E_{j}\right)^{2}} \\
\omega_{j}=\frac{\sigma_{j}}{\sum_{j=1}^{n} \sigma_{j}} \\
\omega_{r j}=\frac{\omega_{i}}{\sum_{j=1}^{r} \omega_{j}} \\
D_{j}=\frac{S_{j}}{X_{j}}(\text { for equation } 1) ; D_{j}=\frac{X_{j}}{S_{j}}(\text { for equation } 2) \\
B_{r=1}^{r} \omega_{\mathrm{rj}}+\sum_{j=1}^{s} \omega_{\mathrm{sj}}+\sum_{j=1}^{t} \omega_{\mathrm{tj}} \\
A=B_{\mathrm{r}} \omega_{\mathrm{r}}+B_{\mathrm{s}} \omega_{\mathrm{s}}+B_{\mathrm{t}} \omega_{\mathrm{t}}
\end{gathered}
$$

Where $x_{i j}$ and $y_{i j}$ were the initial value and standard values of the $j$ th $(j=1,2, \ldots, n)$ index for the $i$ th $(i=1,2, \ldots, 22)$ equipment; $x_{j m i n}$ and $x_{j m a x}$ were the maximum and minimum value of the $j$ th index; $n$ was the sum of indexes ( $r, s$, and $t$ were the number of equipment importance index, production quality problem index of equipment, equipment management index); $E_{j}$ was the mean value of the $j$ th index; $\sigma_{j}$ was the standard deviation for the $j$ th index; $\omega_{j}$ was the weight coefficient of the $j$ th index; $\omega_{r j}$ was the weight of the $j$ th index in equipment importance index, the equations for equipment quality problem index and equipment management index were similar with equation (6); $\omega_{\mathrm{r}}$ was the weight of the equipment importance index, similar with equipment quality problem index and equipment management index; $D_{j}$ was the value of the $j$ th index; $S_{i}$ was the current value of the $j$ th index; the $X_{i}$ was the standard value for the $j$ th index; $B_{\text {r }}$ was the index value of equipment importance index, with the same equation for equipment quality problem index and equipment management index; $A$ was the overall equipment quality importance. 
Table 1 Established evaluation index system of equipment quality importance for wind/photovoltaic energy storage and transmission demonstration project

\begin{tabular}{|c|c|c|}
\hline Target layer & Criterion layer & Index layer \\
\hline \multirow{23}{*}{$\begin{array}{c}\text { overall } \\
\text { equipment } \\
\text { quality } \\
\text { importance }\end{array}$} & \multirow{8}{*}{$\begin{array}{c}\text { equipment } \\
\text { importance index }\end{array}$} & core status \\
\hline & & engineering efficiency influence \\
\hline & & engineering progress influence \\
\hline & & production \\
\hline & & components similarity \\
\hline & & quality grade \\
\hline & & unnormal operation influence \\
\hline & & security to power distribution network \\
\hline & \multirow{5}{*}{$\begin{array}{l}\text { equipment quality } \\
\text { problem index }\end{array}$} & machining process complexity \\
\hline & & quality inspection information \\
\hline & & insulation test \\
\hline & & characteristic test \\
\hline & & electrical test \\
\hline & \multirow{10}{*}{$\begin{array}{c}\text { equipment } \\
\text { management index }\end{array}$} & on-line monitoring \\
\hline & & real-time running status \\
\hline & & Fault defects and abnormal records \\
\hline & & supplier specialized manufacturing capabilities \\
\hline & & supplier technical scheme solving ability \\
\hline & & maintenance costs \\
\hline & & quality records complete rate \\
\hline & & supplies equipment preservation rate \\
\hline & & quality management system \\
\hline & & quality management system completeness \\
\hline
\end{tabular}

\section{Results and Discussions}

The specific calculated index values of target layer and criterion layer were listed in Table 2. Quality importance of 22 kinds of equipment exists significant difference, and the equipment quality importance sequence in each index of criterion layer matches the importance sequence of target layer, presenting the overall equipment quality importance in wind/photovoltaic energy storage and transmission equipment demonstration project reflects in the operation and management lifecycle obviously and any problem is likely to cause significant loss to wind/photovoltaic energy storage and transmission demonstration project. Meanwhile, the evaluation index values of different equipment in index layer exist importance cross phenomenon, that is mean not all indexes meet the overall importance sequence. Through all the conclusions obtained above we can see, the different function and performance of each equipment decides the difference importance sequence in the specific index of index layer, but the comprehensive importance sequence are similar in target layer and criterion layer with significant law. For further analysis, the calculated evaluation index values of different equipment in 3 layers were used to carry out cluster analysis (Fig. 1). From Fig. 1, 22 kinds of equipment can be divided into 3 categories: the first category is named core equipment, containing wind generator, wind turbine tower, transformer, reactor, switchgear, circuit breaker, isolating switch, box type substation, wind turbine blades and inverter; the second category is named replaceable equipment, containing cable, current transformer, voltage transformer, capacitor switch cabinet, polycrystalline silicon photovoltaic module; the third category is named large-scale production equipment, containing fittings, insulators, cable branch box, lightning arrester, cable accessories and cables. Combined with the grouping results and calculated evaluation values we can see: the overall importance index values of essential equipment are all larger than 0.85; 6 replaceable equipment distributed in 0.70 0.85; 6 large-scale production equipment are all smaller than 0.60 . 
Table 2 Calculated evaluation index values of equipment quality importance for wind/photovoltaic energy storage and transmission demonstration project

\begin{tabular}{|c|c|c|c|c|}
\hline Equipment & $\begin{array}{c}\text { Overall } \\
\text { equipment } \\
\text { quality } \\
\text { importance }\end{array}$ & $\begin{array}{l}\text { Equipment } \\
\text { importance } \\
\quad \text { index }\end{array}$ & $\begin{array}{l}\text { Equipment quality } \\
\text { problem index }\end{array}$ & $\begin{array}{c}\text { Equipment } \\
\text { management } \\
\text { index }\end{array}$ \\
\hline wind generator & 1.000 & 1.000 & 1.000 & 1.000 \\
\hline wind turbine tower & 0.898 & 0.898 & 0.874 & 0.921 \\
\hline transformer & 0.883 & 0.860 & 0.880 & 0.909 \\
\hline reactor & 0.882 & 0.857 & 0.882 & 0.907 \\
\hline switchgear & 0.883 & 0.841 & 0.888 & 0.920 \\
\hline circuit breaker & 0.890 & 0.888 & 0.871 & 0.913 \\
\hline isolating switch & 0.851 & 0.815 & 0.860 & 0.878 \\
\hline box type substation & 0.855 & 0.808 & 0.850 & 0.907 \\
\hline wind turbine blades & 0.897 & 0.875 & 0.885 & 0.931 \\
\hline photovoltaic inverter & 0.856 & 0.828 & 0.847 & 0.894 \\
\hline cable & 0.734 & 0.685 & 0.757 & 0.760 \\
\hline current transformer & 0.766 & 0.660 & 0.822 & 0.814 \\
\hline capacitor & 0.775 & 0.689 & 0.790 & 0.844 \\
\hline voltage transformer & 0.775 & 0.667 & 0.803 & 0.856 \\
\hline switch cabinet & 0.701 & 0.589 & 0.718 & 0.787 \\
\hline $\begin{array}{c}\text { polycrystalline silicon } \\
\text { PV modules }\end{array}$ & 0.729 & 0.554 & 0.819 & 0.814 \\
\hline cables & 0.550 & 0.374 & 0.637 & 0.640 \\
\hline fittings & 0.527 & 0.318 & 0.639 & 0.622 \\
\hline insulators & 0.611 & 0.414 & 0.741 & 0.679 \\
\hline cable branch box & 0.602 & 0.420 & 0.700 & 0.687 \\
\hline lightning arrester & 0.539 & 0.375 & 0.644 & 0.598 \\
\hline cable accessories & 0.565 & 0.377 & 0.667 & 0.651 \\
\hline
\end{tabular}

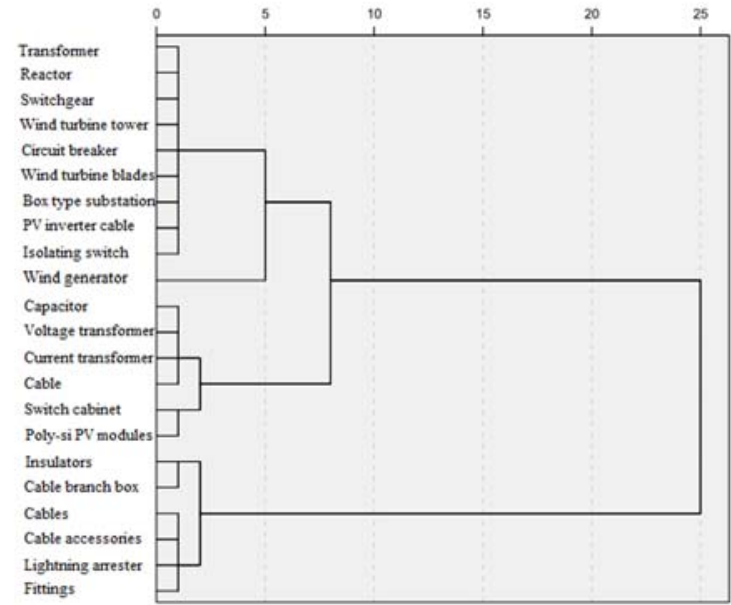

Fig. 1 Clustering of 22 kinds of equipment based on cluster analysis

\section{Conclusion}

(1) The evaluation index system of equipment quality importance was established via analytic hierarchy process from three views of equipment importance index, production quality problem index of equipment and equipment management index: different function and performance of each 
equipment decide the difference importance sequence in specific index, but the comprehensive importance sequence are similar in target layer and criterion layer.

(2) 22 kinds of can be divided into 3 categories via cluster analysis: 10 core equipment; 6 replaceable equipment; 6 large-scale production equipment. Meanwhile, the demarcation intervals for 3 categories were $0.85 \sim 1,0.7 \sim 0.85$ and $0 \sim 0.6$.

\section{References}

[1] Zhao X., Wang J., Liu X., et al. China's wind, biomass and solar power generation: What the situation tells us? Renewable and Sustainable Energy Reviews. Vol. 16 (2012) No. 8, p. 61736182.

[2] Yu L., Xu C. Exploitation and utilization of the wind power and its perspective in China. Renewable \& Sustainable Energy Reviews. Vol. 16 (2012) No. 4, p. 420-424.

[3] Gao M.J., Hui D., Gao Z.H., et al. Presentation of national wind/photovoltaic/energy storage and transmission demonstration project and analysis of typical operation modes. Automation of Electric Power Systems. Vol. 37 (2013) No. 1, p. 59-64.

[4] Saaty T.L. Decision making with the analytic hierarchy process. International Journal of Services Sciences. Vol. 1 (2008) No. 1, p. 83-98.

[5] Rui R., Ye D., Jiang L. Benefit analysis and FGD optimization for designed Power plant based on comprehensive benefit index system. Advanced Materials Research. Vol. 1044-1045 (2014) No. 8, p. 255-258.

[6] Dai Q.H., Liu G.B., Liu M.Y. An evaluation on sustainable development of eco-economic system in small watershed in hilly area of Northeast China. Acta. Geographica. Sinica. Vol. 60 (2005) No. 2, p. 209-218. 